\title{
Percepções do Assistente Social sobre o trabalho que realiza em uma Instituição Filantrópica de Longa Permanência no Distrito Federal
}

\author{
Social Worker's perceptions about the work done in a long-term \\ philanthropic institution in the Federal District
}

\author{
Maria Liz Cunha de Oliveira* \\ Helga Cristina Hedler** \\ Eduarda Vasconcelos dos Santos ${ }^{* * *}$
}

\section{Resumo:}

A presente pesquisa é de natureza descritiva, exploratória e qualitativa, e se detém ao contexto laboral em que atuam os assistentes sociais em Instituição de Longa Permanência para idosos - ILPI na cidade do Núcleo Bandeirante em Brasília- DF. O objetivo desta pesquisa foi analisar as percepções dos assistentes sociais sobre o seu trabalho. A amostra foi de três assistentes sociais. Os dados foram coletados por meio de uma entrevista estruturada. Utilizou-se a análise de conteúdo para a interpretação das respostas. Os resultados indicaram que os assistentes sociais percebem sua responsabilidade enquanto agentes mediadores na garantia de direitos aos mais velhos, contudo o espaço institucional apresentase burocrático e pouco permeável ao potencial desta ação.

Palavras-chave: Pessoa idosa. Instituição asilar. Serviço Social. Contexto laboral. Trabalho. Envelhecimento.

\begin{abstract}
:
The descriptive, exploratory and qualitative research has this look at the labor context in which social workers operate in long-stay institution for elderly in Brasilia, Federal District. The aim of this research was to analyze the perceptions of social workers about their work. The sample was three social workers. Data were collected through a structured interview. We used content analysis for the interpretation of the answers. The results indicated that social workers realize their responsibility as mediating agents in ensuring the older, yet the institutional space presents bureaucratic and not very open to the potential of this action.
\end{abstract}

Keywords: Elderly. Asylum institution. Social Work. Labor context. Work. Aging.

\section{Introdução}

\footnotetext{
* Universidade Católica de Brasília. Doutora em Ciências da Saúde. Professora Universidade Católica de Brasília (UCB). E-mail: lizcunhad@gmail.com

** Universidade Católica de Brasília. Doutora em Psicologia Social, do Trabalho e das Organizações (Psto) pela Universidade de Brasília. Professora e pesquisadora da Universidade Católica de Brasília. E-mail: helga@ucb.br

*** Universidade Católica de Brasília. Assistente Social. Email: eduarda.vasconcelos 213@hotmail.com
} 
Este estudo se debruça sobre o ambiente de trabalho em uma Instituição de Longa Permanência de atendimento a pessoas idosas. O foco é a ação dos assistentes sociais, considerando-os profissionais de mediação na garantia de direitos, entendendo a responsabilidade no cuidado do idoso como parte da responsabilidade da família, da sociedade e do Estado complementarmente como explicitam as legislações vigentes.

Reconhece-se o avanço no número de idosos no Brasil, assim como da legislação que garante seus direitos, sendo Instituições de Longa Permanência (ILPI) para idosos importantes instituições nesse sentido.

Estudar o contexto laboral em que atuam os assistentes sociais é importante para compreender os desafios enfrentados e limites no exercício de sua profissão. Utilizou-se uma amostra de três assistentes sociais, entrevistados para avaliar a percepção sobre o trabalho em uma ILPI na cidade do Núcleo Bandeirante em Brasília.

O presente trabalho objetiva apresentar os achados da pesquisa e se organiza em duas partes. A primeira parte caracteriza o tema e discute a questão do idoso na sociedade brasileira, assim como o papel do assistente social como profissional na mediação da defesa de direitos dos idosos em um ILPI em Brasília. Na segunda parte do texto apresentam-se os dados da pesquisa a partir dos seguintes aspectos: o papel do assistente social em uma ILPI; o trabalho do Assistente Social em uma ILPI; desafios e limitações vivenciadas pelos assistentes sociais na ILPI; importância e contribuição do assistente social na vida dos idosos e na ILPI; instrumentais utilizados para viabilizar o atendimento social aos idosos. Na conclusão apresentam-se as principais reflexões sobre os achados e apontam-se os horizontes de ampliação das discussões sobre o tema.

\section{Caraterização do tema}

Com a promulgação da Lei no 10.741, conhecida como Estatuto do Idoso, em 2003 (BRASIL, 2003), os indivíduos de 60 anos ou mais passaram a fazer parte de uma parcela da população que possui direitos específicos regidos e legitimados por lei estatutária.

O contingente de pessoas idosas no Brasil, segundo a Política Nacional do Idoso (BRASIL, 1994), era de 20.590 .599 milhões, ou seja, aproximadamente 10,8 \% da população total. Em 2010, segundo o Instituto Brasileiro de Geografia e Estatística (IBGE, 2011), a faixa etária de 80 anos, a mais numerosa, era composta por 2.935 .585 pessoas, 
representando $14 \%$ da população idosa brasileira. Este é o novo cenário demográfico do século XXI.

Contudo, as políticas públicas não acompanham as necessidades criadas pelo crescimento demográfico. Ainda predomina o despreparo do Estado e a ausência de serviços para tal população.

Quando se fala do idoso, trata-se de um sujeito de direitos com características peculiares. Sabe-se que envelhecer pode ser somente um processo natural do tempo, mas que em alguns casos implica revezes e impedimentos das condições de vida que permeiam a história destes indivíduos. Envelhecer é ver transformarem-se condições físicas, biológicas, psicológicas, sociais, de renda, assim como de convívio familiar e comunitário.

Nessa fase da vida, o ser pode necessitar de auxílios e intervenções para a manutenção de seu bem-estar. Born (2008) afirma que a legislação brasileira dá centralidade à família como espaço primordial de cuidado e proteção aos seus membros. A Constituição Federal de 1988 (BRASIL, 1988), a Política Nacional do Idoso, de 1994 (BRASIL, 1994) e o Estatuto do Idoso (BRASIL, 2003), reconhecem a responsabilidade compartilhada entre família, sociedade e Estado no cuidado com o idoso, priorizando o atendimento em seu domicílio, pela sua família. Sendo o Estado e a sociedade suplementares e não somente subsidiários na ausência ou carência da família (MIOTO, 2010).

Entretanto, questiona-se como seria o atendimento ao idoso em uma ILPI? O Estatuto do Idoso (BRASIL, 2003), Cap.II, art. 49 prevê que:

[...]. As entidades que desenvolvam programas de institucionalização de longa permanência adotarão os seguintes princípios:

I. Preservação dos vínculos familiares;

II. Atendimento personalizado e em pequenos grupos;

III. Manutenção do idoso na mesma instituição, salvo em caso de força maior;

IV. Participação do idoso em atividades comunitárias, de caráter interno e externo;

V. Observância dos direitos e garantias dos idosos;

VI. Preservação da identidade.

Assim, o cenário de um bom atendimento ao idoso em uma sociedade onde a pirâmide etária tem demonstrado ampliação desse contingente populacional deveria ser de famílias, Estado e sociedade em condições adequadas para atender aos idosos. 
Entretanto, para Pereira-Pereira (2006), em vista da dimensão política e das novas estruturas governamentais, o Estado tem diminuído o compromisso com a efetivação dos direitos sociais com uma série de ações excludentes como: a elevação da idade para o acesso às aposentadorias; aumento da carga tributária dos contribuintes; ou ainda reduzindo a proteção social pública a partir da perspectiva da focalização. Sobre isso diz Mioto (2010) que, para de fato garantir direitos, às políticas públicas precisam possuir caráter universal, pois quando se tornam focalizadas fortalecem a atuação do mercado como provedor da proteção social ou caminham no sentida da excessiva responsabilização da família.

Ainda segundo Mioto (2010), quando falta a ação do Estado por meio de políticas públicas os serviços sociais acabam sendo assumidos pelas famílias, como por exemplo, o cuidado com a pessoa idosa. Born (2008, p. 53) complementa que "até agora a maior carga de responsabilidade recai sobre a família, especialmente sobre a mulher, que sem preparo anterior, se vê transformada em cuidadora da pessoa idosa".

Para evitar tal sobrecarga às famílias e à sociedade, ou quando estas instâncias têm incapacidade no atendimento aos seus membros idosos, deve, portanto, o Estado avançar na garantia de serviços a este público.

Um exemplo de serviço necessário neste momento etário são as chamadas Instituições de Longa Permanência. O Estatuto do Idoso (BRASIL, 2003) é o primeiro instrumento normativo a introduzir o termo: "Instituição de Longa Permanência para idosos (ILPI)". A expressão é uma adaptação não literal do termo utilizado pela Organização Mundial de Saúde "Long-Term Care Institution" que quer dizer "Cuidados Prolongados”ou “Cuidados de Longa Duração" (COSTA, 2004; BORN, 2008).

Os marcos legais que regem o funcionamento das ILPIs no País: a Constituição Federal de 1988 (BRASIL, 1988), a Política Nacional do Idoso (BRASIL, 1994) e o Estatuto do Idoso (BRASIL, 2003), reconhecem a responsabilidade compartilhada entre família, sociedade e Estado no cuidado com o idoso, priorizando o atendimento em seu domicílio e pela sua família. Estado e sociedade suplementam e não mais suprem a ausência ou carência da família (MIOTO, 2010).

Para além das questões legais cabe uma breve reflexão sobre as características das ILPIs. De acordo com Faleiros e Justo (2007) as ILPIs são espaços contraditórios, com 
temporalidades e histórias entrecruzadas onde existem normas não escolhidas pelos residentes, com um espaço estruturado por funções coletivas, relações hierarquizadas de poder, numa separação do espaço institucional da vida sociocomunitária e da vida familiar, com restrições à autonomia, mas com expressões de resistência como desejos, insatisfações, discordâncias, invenção de espaços e imaginários próprios. Embora,

[...] o padrão de qualidade no atendimento institucional deve se pautar na valorização da história do idoso, no respeito à sua individualidade, autonomia e privacidade, na preservação dos vínculos e na participação na comunidade. A assistência religiosa deve ser oferecida de acordo com a crença para aqueles que desejarem (POLLO; ASSIS, 2008, p.35).

Convergente com este entendimento, Vieira (2003) também ressalta que as ILPIs precisam ser entendidas não como local que acolhe idosos rejeitados ou abandonados pela família ou pela sociedade, mas como uma possível escolha do idoso a um local onde viver e se constituir enquanto pessoa, gerando inclusive a sensação de pertencimento.

As ILPIs podem ser instituições governamentais ou não governamentais, de caráter residencial, destinadas ao domicílio coletivo para pessoas com idade igual ou superior a 60 anos, com ou sem suporte familiar, em condições de liberdade, dignidade e gozo de cidadania. O Estatuto do Idoso (BRASIL, 2003) - Cap. IX, Art. $37 \S 1$ - - eleva o atendimento das ILPIs e casas-lares ao status de instituições prestadoras de serviços fundamentadas no direito das relações de consumo, e obriga as instituições, independentemente de sua personalidade jurídica, a firmar um contrato de prestação de serviços com a pessoa abrigada ou seu familiar/curador, no caso de incapacidade, e a ter seus serviços e programas inscritos no Conselho do Idoso e na Vigilância Sanitária.

Tanto as instituições públicas como as de caráter não governamental atendem as normas e se inserem no escopo de serviços de Alta Complexidade da Política de Assistência Social ${ }^{1}$, tendo em vista que são serviços destinados a famílias e/ou indivíduos que perderam seus vínculos familiares ou que estejam em situação nas quais não tenham condições de convívio familiar ou comunitário.

\footnotetext{
${ }^{1}$ A política em questão estabelece que "a assistência social, direito do cidadão e dever do Estado, é Política de Seguridade Social não contributiva, que provê os mínimos sociais, realizada através de um conjunto integrado de iniciativa pública e da sociedade, para garantir o atendimento às necessidades básicas". (BRASIL, 2004, p.31).
} 
A Política de Assistência Social pode cofinanciar estes serviços diretamente ou por meio de convênios locais, com recursos advindo do Fundo Nacional de Assistência Social (FNAS) e transferidos para os Fundos Municipais ou Estaduais de Assistência Social a valores (pisos de proteção social) estabelecidos pela Norma Operacional Básica (NOB/SUAS) e regulados pela portaria MDS no. 440 de 23 de agosto de 2005 (BRASIL, 2005).

Estas instituições prestam serviços complexos e multifacetados à população idosa, por isso, apesar de regidos pela Política de Assistência Social, as instituições de longa permanência para idosos também se situam na esfera da saúde, quando se trata da fiscalização. E ainda, por serem consideradas pela legislação como domicílios coletivos também deveriam ser objeto de uma política habitacional.

A Resolução da Diretoria Colegiada (RDC) 283, de 26 de setembro de 2005, da Agência Nacional de Vigilância Sanitária (ANVISA, 2005), estabelece regras de funcionamento, organização física, sanitária e de recursos humanos segundo o grau de dependência do idoso atendido, definida de acordo com a legislação de 2001, do então Ministério da Previdência e Assistência Social (Portaria MPAS/73) que estabelece as “Normas de Funcionamento de Serviços de Atenção ao Idoso no Brasil” (BRASIL, 2001).

Reafirmando os princípios estabelecidos pelo Estatuto do Idoso (BRASIL, 2003), a RDC 283 exige que a instituição possua alvará sanitário, comprove inscrição no Programa Nacional do Idoso, que esteja legalmente constituída, possua estatuto registrado, registro de entidade social e regimento interno, e possua um responsável técnico com nível superior.

Nesta Resolução está explicito que "o atendimento integral institucional" é aquele prestado em instituição asilar para idosos sem família, vulneráveis, oferecendo-lhes serviços na área social, psicológica, médica, de fisioterapia, de terapia ocupacional, de enfermagem, de odontologia e outras atividades específicas para este segmento social.

Dito isto, observa-se que sendo necessário na proteção de um público em constante expansão como é o idoso, o campo de trabalho das ILPIs é essencialmente social. Estas instituições envolvem-se em uma relação direta entre a família, o Estado e a sociedade, e que, embora atendam exigências de outras políticas, referem-se substancialmente à política de Assistência Social. 
Isto significa que as equipes de atendimento devem ser prioritariamente multidisciplinares e dinâmicas, contudo tendo em vista a peculiaridade do atendimento social, observa-se a relevância e a presença primordial do assistente social como componente destas equipes.

Segundo a NOB/RH SUAS a equipe das ILPIs compõem-se obrigatoriamente de:

Quadro 1. Instituições de Longa Permanência para Idosos -ILPIs, equipe de referência para atendimento direto

\begin{tabular}{|l|l|}
\hline \multicolumn{1}{|c|}{ PROFISSIONAL/FUNÇÃo } & \multicolumn{1}{c|}{ ESCOLARIDADE } \\
\hline Coordenador & nível superior ou médio \\
\hline Cuidadores & nível médio \\
\hline 1 Assistente Social & nível superior \\
\hline 1 Psicólogo & nível superior \\
\hline $\begin{array}{l}\text { 1 Profissional para desenvolvimento de atividades } \\
\text { socioculturais }\end{array}$ & nível superior \\
\hline Profissional de limpeza & nível fundamental \\
\hline Profissional de alimentação & nível fundamental \\
\hline Profissional de lavanderia & nível fundamental \\
\hline
\end{tabular}

Fonte: Brasil (2009, p.23).

Observe-se que, para a instituição oferecer serviços de longa permanência, é necessário o trabalho do assistente social na sua equipe básica de atendimento. Sabe-se da responsabilidade do assistente social na defesa de direitos e sua competência privativa em ações de Serviço Social em conformidade com o seu Código de Ética profissional (CONSELHO FEDERAL DE SERVIÇO SOCIAL, 1993).

Observa-se ainda a urgente necessidade de ampliação de serviços para a pessoa idosa no País, de serviços que sejam complementares à ação da família, e do assistente social como mediador das relações sociais, na perspectiva da defesa de direitos (PONTES, 2007).

Por tudo isso, esta pesquisa se dedica à percepção dos assistentes sociais sobre este ambiente de trabalho, no atendimento ao idoso. Sendo um serviço essencial, esperase que estes profissionais, em função de sua formação e compromisso ético com a defesa de direitos consigam avaliar e indicar caminhos e formas de atuação nas ILPIs.

Assim, o objetivo deste estudo é investigar a percepções do assistente social sobre o trabalho cotidiano que realiza em uma ILPI. 
Trata-se de um estudo descritivo e exploratório, de natureza qualitativa em virtude do potencial de apreensão crítica da realidade (GIL, 1999). Segundo essa definição depreende-se que os significados atribuídos pelos sujeitos a sua experiência social cotidiana permitem um desvelamento maior das relações sociais e também dos mecanismos de dominação/exclusão da sociedade capitalista. Para Minayo (1996), o objetivo de trabalho das pesquisas sociais é qualitativo, havendo imbricação entre o pesquisador e a natureza do seu trabalho. A pesquisa qualitativa busca entender os fatos em seu ambiente natural por meio de sentido e interpretação dos fenômenos, de acordo com os significados de quem os vivencia.

O local do estudo foi escolhido em função da possibilidade de acesso, a saber, o Lar de Idosos Maria Madalena, fundado em 1980 localizado no Núcleo Bandeirante - Distrito Federal, Brasil. O Lar é uma instituição regularmente reconhecida como ILPI, de caráter filantrópico e sem fins lucrativos. Atualmente residem na instituição 96 idosos, seu quadro profissional conta com o trabalho de 03 assistentes sociais, 02 enfermeiros, 04 técnicos de enfermagem e 16 cuidadores.

O projeto de pesquisa foi encaminhado para o Comitê de Ética em Pesquisa com Seres Humanos - CEP da Universidade Católica de Brasília (UCB) e aprovado pelo $\mathrm{N}^{\circ} \mathrm{CAAE}$ 38101514.0.0000.0029. Todos os participantes assinaram um Termo de Consentimento Livre e Esclarecido.

A amostra foi não probabilística e intencional, participaram todos os assistentes sociais que trabalham na instituição, ou seja, três profissionais.

A coleta de dados se deu por meio da entrevista aberta em duas partes: 1 caracterização dos participantes (sexo, idade, formação); e 2 - roteiro da entrevista, propriamente dito, focalizado no tema da percepção do papel do assistente social sobre o seu trabalho em uma ILPI.

As perguntas relacionadas ao papel dos assistentes sociais na instituição foram: qual o papel dos assistentes sociais em uma ILPI? Quais são os principais desafios e limitações vivenciadas pelo(a) assistente social na ILPI? Qual a contribuição do trabalho dos assistentes sociais na vida dos idosos e na ILPI? Quais são os instrumentais utilizados para viabilizar o atendimento social aos idosos da ILPI? 
Após autorização para a realização da pesquisa, as entrevistas foram agendadas conforme a disponibilidade dos participantes.

Reconhecemos as limitações da entrevista como técnica de coleta de dados. Para Gil (1999, p. 118), as principais limitações da técnica de entrevista são, "a falta de motivação do entrevistado para responder as perguntas que lhe são feitas; a inadequada compreensão do significado das perguntas", em especial a primeira limitação aqui apontada foi vivenciada nesta pesquisa.

Os dados foram tratados à luz da análise de conteúdo, utilizando-se a técnica de análise temática. Para Minayo (2010), a análise de conteúdo é a expressão mais comumente usada para representar o tratamento dos dados de uma pesquisa qualitativa.

\section{Resultados e discussão}

A pesquisa oferece importantes insumos para conhecer a percepção dos profissionais sobre o trabalho em ILPI. A começar por uma importante reflexão quanto ao perfil profissional. Como é sabido, a característica de feminilização permeou por muito tempo a trajetória histórica do Serviço Social. Segundo Craveiro e Machado (2011), na contemporaneidade, ainda pode-se observar a prevalência das mulheres na profissão de Serviço Social, visto que, no imaginário da população, a mulher possui as características mais evidentes para o exercício do Serviço Social, no entanto essa realidade vem se modificando.

Situação observada na instituição pesquisada, onde se encontrou dois assistentes sociais do sexo masculino e uma do sexo feminino. No caso dos assistentes sociais no Lar Maria Madalena (ILPI) a realidade foge à regra, a instituição mostra-se diferente, pois tem predominância masculina entre os profissionais de Serviço Social.

No que diz respeito ao tempo de graduação todos possuem mais de um ano e meio de atuação na área e no máximo dois anos de formados. lamamoto (2011) chama atenção para o fato de (mesmo considerando o pouco tempo de atuação dos profissionais neste caso) os(as) assistentes sociais serem capazes de decifrar uma dada realidade e, a partir dessa realidade, construir sua proposta de trabalho de forma criativa, preservando e efetivando direitos, a partir das demandas que surgem no cotidiano. 
Apresentado o perfil dos profissionais dividimos a apresentação dos dados em cinco categorias, quais sejam: o papel do assistente social em uma ILPI; o trabalho do Assistente Social em uma ILPI; desafios e limitações vivenciadas pelos assistentes sociais na ILPI; importância e contribuição do assistente social na vida dos idosos e na ILPI; instrumentais utilizados para viabilizar o atendimento social aos idosos.

\section{O papel dos assistentes sociais em uma ILPI}

A atuação do profissional de Serviço Social é baseada no atendimento às demandas referentes ao processo de acolhimento de idosos que envolvem tanto aos aspectos sociais quanto aos aspectos psicológicos. Neste sentido, vale lembrar a necessidade do trabalho realizado de forma interdisciplinar entre psicólogos e assistentes sociais (EIDELWEIN, 2007, p.305). A autora considera a proximidade dos objetos de estudo do Serviço Social e da Psicologia Social na vertente mais crítica, pois, o social sobre o qual esses profissionais se debruçam "não é compreendido como algo natural, evidente, mas como resultado de uma construção histórica decorrente de lutas entre forças contraditórias".

Assim, cabe aqui desenvolver uma reflexão sobre as possibilidades de construção de saberes e práticas interdisciplinares decorrentes da relação dialógica entre essas áreas de conhecimento através de questionamentos voltados às próprias áreas.

Sendo que o profissional precisa conhecer os meios de viabilização e garantia dos direitos assegurados por lei para que possa realizar a intervenção necessária. Seguem assim as percepções dos profissionais entrevistados sobre o tema:

E1: [...] o conhecimento das políticas faz com que o Assistente Social tenha uma autonomia dentro da instituição conhecendo melhor a realidade dos idosos para melhor intervir e promover ações de bem-estar e lazer.

E2: O papel do assistente social na instituição é garantir o direito e qualidade de vida dos idosos residentes, na qual cada assistente social tem que realizar um trabalho de qualidade da instituição [...] para tanto tem que ter um mínimo de conhecimento sobre a política do idoso, saber passar informações, acolher $e$ acompanhar as atividades dos idosos.

A visão dos profissionais se coaduna com o que indica o documento de Tipificação Nacional dos Serviços Socioassistenciais (BRASIL, 2009a) quando afirma que no acolhimento institucional deve ser desenvolvido um trabalho social, no qual os 
profissionais devem acolher os idosos, escutá-los, proporcionar o desenvolvimento do convívio familiar, grupal e social.

\section{O trabalho dos assistentes sociais em uma ILPI}

No que se refere à prática profissional, um importante reconhecimento dos profissionais deve ser a respeito da complexidade da realidade conforme no diz Faleiros (2014, p. 708):

São demandas complexas tanto por efetivação de direitos como por cuidados específicos que exigem dos profissionais a análise das relações gerais e particulares dessas condições e do poder de enfrentá-las, o que implica trabalhar a correlação de forças.

Fica claro, portanto, que as demandas por serviços sociais ou políticas sociais expressam as desigualdades econômicas, de inclusão/exclusão social, de dominação de gênero, de relações de poder e violência nos conflitos familiares, de relação com o crime, com o uso de drogas, com a enfermidade, com a precarização das condições sociais e familiares. Espera-se, portanto, uma ação condizente com estas perspectivas.

Contudo a pesquisa aponta que, no que se refere à instituição estudada, os aspectos operacionais voltam-se mais para a dimensão burocrática, considerando as demandas institucionais, dos usuários e do Serviço Social na organização de funções, favorecendo que o trabalho de todos seja realizado, que "o serviço funcione", conforme os depoimentos:

E1: [...] Eu atuo na parte externa, nas parcerias com as redes próximas a unidade do Lar Maria Madalena, na busca de parceiros e benefícios tanto previdenciários quanto relacionados à saúde para os idosos [...] esta instituição é filantrópica e necessita destes parceiros principalmente na questão financeira $[\ldots]$.

E2: [...] Eu fico responsável pelas entrevistas domiciliares junto com familiares $e$ idosos, elaboração de relatórios. Nestas entrevistas eu analiso a necessidade do idoso ser institucionalizado [...].

E3: [...] Eu fico na parte interna, ou seja, responsável pela resolução de demandas da instituição, como ir ao banco com os idosos, em consultas, sejam elas com os idosos ou funcionário[...].

Assim, podemos afirmar que para os participantes deste estudo, a função do assistente social volta-se fortemente para atender às exigências da instituição. As demandas coletivas para o Serviço Social são apresentadas tanto institucionalmente 
como pela intervenção profissional ou pela própria organização da sociedade, na defesa de direitos, de mudanças nas políticas públicas, entre outros (FALEIROS, 2014).

As instituições aparecem como mecanismos reguladores da crise capitalista, onde o profissional se insere para viabilizar direitos, esbarrando muitas vezes em elementos constitutivos da instituição na qual os profissionais estão vinculados.

O trabalho do assistente social em uma ILPI implica uma relação com sujeitos particulares numa estrutura capitalista. No entanto, essa relação se faz também em contextos particulares, principalmente em instituições onde há contradições, inscrevendo-se o próprio Serviço Social nesses conflitos e contradições. A intervenção profissional, portanto, não é resultado de um relacionamento interindividual, mas uma relação de poder hegemônico e contra-hegemônico, retomando a expressão gramsciana (GRAMSCl, 1980).

A prática profissional é um enfrentamento enquanto relação complexa e contraditória de poder, recursos, valores, linguagem, dispositivos, estratégias, operações, visões de mundo, situações sociais de desigualdade, sofrimento, exclusão. Enfrentamento relacional de determinações econômicas, políticas, sociais, culturais, entre outras, com dinâmica histórica e política da contestação e da expressão de si e da própria sociedade (FALEIROS, 2014).

É nesse contexto que a prática profissional expressa os conflitos e contradições da estrutura capitalista, da política e das relações de atendimento.

Verificamos que no cotidiano da instituição, o profissional ultrapassa suas atribuições e que, por não ter uma equipe multidisciplinar, acaba assumindo funções que não são inerentes ao Serviço Social, impossibilitando os mesmos de exercer amplamente o que concerne a sua atuação profissional, como por exemplo, a celebração de convênios com serviços públicos e privados, mediante elaboração de projetos voltados para beneficiar a instituição, como estratégia de manutenção do próprio equipamento.

\section{Os desafios e limitações vivenciados pelos assistentes sociais no trabalho realizado em uma ILPI}

Há uma real tensão entre a garantia da autonomia do profissional diante da relação de troca da sua força de trabalho especializada, diante de seus empregadores, tais como: 
Estado, empresários, organizações e etc. lamamoto (2011, p. 215) afirma que "O significado social do trabalho profissional do assistente social depende das relações que estabelece com os sujeitos sociais que contratam, os quais personificam funções diferenciadas na sociedade".

Os empregadores determinam as necessidades sociais as quais o trabalho do assistente social deve responder, delimitam a matéria sobre a qual incide esse trabalho interferindo nas condições em que se operam os atendimentos assim como os efeitos na reprodução das relações sociais.

Nas relações de poder os empregadores impõem as exigências trabalhistas e ocupacionais aos seus empregados e mediam as relações com os trabalhos coletivos por eles realizados, é sob estas condições que o assistente social tem encontrado formas de exercer a sua função aliado a coletividade da classe trabalhadora.

E1: [...] O grande desafio e limitação são as relações de poder e a falta de aproximação com as redes da localidade em que fica a ILPI, pois falta colaboração para resoluções de problemas com as redes de hospitais.

Constatamos a fragilidade das políticas públicas dificultando as ações dos profissionais do Serviço Social, no que se refere à sua articulação com a rede de atendimento a saúde.

No cotidiano profissional a inversão daquilo que está previsto na teoria, ou seja, a intersetorialidade definida por Inojosa (2001, p. 105) como a "articulação de saberes e experiências com vistas ao planejamento, para a realização e a avaliação de políticas, programas e projetos, com o objetivo de alcançar resultados sinérgicos em situações complexas". Acreditamos que o profissional deve buscar ações que contribuam com a intersetorialidade para que possa proporcionar o acesso aos direitos dos idosos, seja no âmbito das políticas públicas de saúde e da assistência social, através de parcerias com os órgãos públicos.

\section{Importância e contribuição do assistente social na vida dos idosos e na ILPI}

Apesar dos entraves institucionais, é sabido que o Serviço Social tem grande importância na articulação e intervenção das demandas apresentadas na instituição, 
colocando em foco sempre o idoso, que é o sujeito principal de qualquer ação. Isso nos afirmam os entrevistados:

E2:[...] o assistente social é importante na resolução de demandas como INSS, CRAS, auxilio funeral, entre outros, que possibilita aos idosos manterem o acesso aos seus direitos, além de proporcionar bem estar ao mesmo.

E3: O profissional tem papel e importância fundamental na questão da garantia de direito aos idosos, primeiro por ser uma porta de entrada, os idosos chegam encaminhados pela SEDEST.

A relação do profissional com os demandantes de serviços pode configurar uma confrontação, como a alienação geral imposta pelo capital que considera a submissão como natural, bem como a vivência dessa alienação na história pessoal. $O$ assistente social além de intermediar conflitos, usa de articulação, realiza atendimento das demandas, encaminhamentos para a rede de serviços públicos, principalmente à saúde, dentre outros. Divulga informações, dá orientações sobre os programas e projetos que venham a ser realizados na instituição. Planeja, organiza e executa atividades que são propostas para promover a melhoria da qualidade de vida na velhice.

O dilema ético do exercício profissional está presente na ação profissional não só como código de conduta, mas como maneira de assegurar os direitos humanos nas formas de direitos sociais, políticos, culturais, econômicos, concretos.

\section{Instrumentais utilizados para viabilizar o atendimento social aos idosos}

Na perspectiva da garantia de direitos e a mediação profissional com as famílias, observa-se que os instrumentos de trabalho são importantes armas políticas. Os assistentes sociais precisam ter consciência do saber que acumulam, e do seu uso na construção e busca de estratégias de enfrentamento para que as ações interventivas sejam direcionadas com base no compromisso com a ampliação e garantia de direitos (FÁVERO; MELÃO; JORGE, 2010).

Os profissionais visualizam os instrumentos que são utilizados e as atividades que realizam, mencionam a impressão do seu olhar especializado nos relatórios e encaminhamentos. Apesar de existirem algumas lacunas no que se refere à sistematização, dando um enfoque mais tecnicista à atuação profissional, as ações que os profissionais realizam estão em consonância com ações do assistente social pautadas na lógica da garantia de direitos. 
E1: São instrumentos de trabalho, como entrevistas, análises sociais, relatórios, levantamento de recursos, encaminhamentos, visitas domiciliares, dinâmicas de grupo, pareceres sociais, contatos institucionais, plano de trabalhos, prontuários, entre outros, que são a forma mais eficaz para prestar um atendimento aos idosos institucionalizados.

O assistente social é responsável por fazer uma análise da realidade social e institucional, e intervir para melhorar as condições de vida das pessoas. No entanto, relações com o público demandante dos serviços sociais estão demarcadas por critérios institucionais, informes, relatórios, entrevistas, exigências cada vez mais minuciosas e normas cada vez mais rígidas. Essa contradição entre as normas ou prescrições e o exercício do trabalho criativo podem levar ao sofrimento no trabalho, como acentua Dejours (1999).

A adequada utilização desses instrumentos requer uma contínua capacitação profissional que busque aprimorar seus conhecimentos e habilidades nas suas diversas áreas de atuação.

\section{Considerações finais}

O ambiente da ILPI pesquisada parece transparecer às contradições e dificuldades da vida em sociedade. Observa-se claramente a dicotomia entre o necessário e o possível.

Apesar do avanço na perspectiva dos direitos, do conjunto de leis, bem como da formulação de políticas públicas voltadas para a velhice, com o intuito de ampliar a cidadania e atender à demanda da sociedade, na prática, faz-se necessário que os direitos estabelecidos dispostos em legislação sejam efetivados e que os idosos sejam protagonistas de sua própria história. Os profissionais de Serviço Social são importantes na mediação e construção desta emancipação.

Contudo, a percepção dos assistentes sociais a respeito do seu trabalho na ILPI está inserida no contexto da produtividade, das exigências burocráticas e envolve a expressão de um movimento que articula conhecimentos e luta por espaços no mercado de trabalho.

Os profissionais demonstram importante clareza de seus objetivos e principalmente o papel transformador e mediador, contudo apontam os entraves institucionais como fator a ser considerado.

Nesse contexto, é preciso levar em conta as condições de trabalho e ao mesmo tempo os interesses, os desejos e as demandas, que podem ser pessoais e coletivas, 
exigindo uma diversidade de intervenções e ações como estratégias complexas diante da correlação de forças em que se insere a questão do idoso que reside em uma ILPI.

O presente estudo não esgota o tema, mas atendeu ao objetivo inicial proposto de caracterizar e compreender os aspectos relacionados à atuação, os desafios e os limites da inserção e vivência profissional em uma ILPI. Apresentam-se acima de tudo, desafios à atuação na perspectiva da garantia de direitos. Sugere-se que em pesquisas futuras as percepções dos assistentes sociais aqui levantadas sirvam de base para novos questionamentos e desenvolvimento do tema junto a outros grupos maiores de instituições.

\section{Referências}

ANVISA - Agência Nacional de Vigilância Sanitária. Resolução RDC no 283, de 26 de setembro de 2005. Aprova o Regulamento Técnico que define normas de funcionamento para as Instituições de Longa Permanência para Idosos. Disponível em: <http://sbgg.org.br/wpcontent/uploads/2014/10/ rdc-283-2005.pdf>. Acesso em: 01 junho de 2014.

BORN, T. (Org.). Cuidar Melhor e Evitar a Violência: Manual do Cuidador da Pessoa Idosa. Brasília: Secretaria Especial dos Direitos Humanos Subsecretaria de Promoção e Defesa dos Direitos Humanos, 2008.

BRASIL. Conselho Nacional de Assistência Social. Resolução 145, de 15 de outubro de 2004. Disponível em: <http://www.mds.gov.br/webarquivos/publicacao/ assistencia_social/ Normativas/PNAS2004pdf>. Acesso em: 22 jul. 2016.

BRASIL. Constituição (1988). Constituição da República Federativa do Brasil. 1988. Disponível em: <http://www.planalto.gov.br/ccivil_03/Constituicao/ Constitui\%C3\%A7ao.htm>. Acesso em: 14 dez. 2014.

BRASIL. Lei 10.741, de 10 de outubro de 2003. Dispõe sobre o Estatuto do Idoso e dá outras providências. Disponível em: <http://www2.camara.leg.br/legin/fed/lei/2003/lei10741-1-outubro-2003-497511-normaatualizada-pl.pdf>. Acesso em: 14 dez. 2014.

BRASIL. Lei 8.842, de 4 de janeiro de 1994. Dispõe sobre a Política Nacional do Idoso, cria o Conselho Nacional do Idoso e dá outras providências. Disponível em:

<http://www.planalto.gov.br/ccivil_03/leis/L8842.htm>. Acesso em: 14 dez. 2014.

BRASIL. Ministério do Desenvolvimento Social e Combate à Fome. Tipificação Nacional de Serviços Socioassistenciais. Brasília, DF, 2009a. Disponível em:

<http://www.assistenciasocial.al.gov.br/legislacao/Tipificacao_servicos_socioassistenciais .pdf/at_download/file>. Acesso em: 22 jul. 2016. 
BRASIL. Ministério do Desenvolvimento Social e Combate à Fome. Norma Operacional Básica de Recursos Humanos do SUAS NOB/ RH/SUAS. Brasília, DF, 2009b. Disponível em: <http://www.mds.gov.br/cnas/politica-e-nobs/nob-rh_08-08-2011.pdf/>. Acesso em: 22 jul. 2016.

BRASIL. Ministério do Desenvolvimento Social e Combate à Fome. Portaria no 440, de 23 de agosto de 2005. Regulamenta os Pisos da Proteção Social Especial estabelecidos pela Norma Operacional Básica - NOB/SUAS, sua composição e as ações que financiam.

Brasília, DF, 2005. Disponível em: <http://www.mds.gov.br/suas/ noticias/port_440.pdf>. Acesso em: 14 dez. 2014.

BRASIL. Portaria SAS-073, de 10 de maio de 2001. Estabelece Normas de Funcionamento de Serviços de Atenção ao Idoso no Brasil. Disponível em:

<http://direitodoidoso.braslink.com/05/portarias.html>. Acesso em: 14 dez. 2014.

CONSELHO FEDERAL DE SERVIÇO SOCIAL. Código de Ética Profissional do/da Assistente Social. Lei 8662 de 1993. Disponível em: <http://www.cfess.org.br/arquivos/ CEP_CFESSSITE.pdf>. Acesso em: 22 jul. 2016.

COSTA, E. F. A. Análise de Soro prevalência para as infecções pelos vírus das hepatites $B e$ C em idoso residentes em asilos no município de Goiânia-GO. 2004. Dissertação (Mestrado em Medicina Tropical) - Instituto de Patologia Tropical e Saúde Pública, Universidade de Goiás, 2004.

CRAVEIRO, A.V.; MACHADO, J.G.V.C. A predominância do sexo feminino na profissão do Serviço Social: uma discussão em torno desta questão. In: SIMPÓSIO GÊNERO E POLÍTICAS PÚBLICAS, 2., 2011. Londrina. Anais. Disponível em:

<http://www.uel.br/eventos/gpp/pages/arquivos/jessica.pdf>. Acesso em: 20 ago. 2014.

DEJOURS, C. A banalização da injustiça social. Rio de Janeiro: FGV, 1999.

EIDELWEIN, K. Psicologia Social e Serviço Social: uma relação interdisciplinar na direção da produção de conhecimento. Revista Textos \& Contextos. Porto Alegre v. 6, n. 2, p. 298313, jul./dez. 2007.

FALEIROS, N. P.; JUSTO, J. S. O idoso asilado: a subjetividade intramuros. Revista Brasileira de Geriatria e Gerontologia, Rio de Janeiro, v. 10, n. 3, p. 327-337, 2007.

FALEIROS, V. P. O Serviço Social no cotidiano: fios e desafios. Serviço Social \& Sociedade, São Paulo, n. 120, p. 706-722, out./dez. 2014.

FÁVERO, E. T.; MELÃO, M. J. R.; JORGE, M. R. T. Serviço Social e o campo sócio jurídico: reflexões sobre o rebatimento da questão social no trabalho cotidiano. In: FORTI, V.; GUERRA, Y. Serviço Social: temas, textos e contextos. Rio de Janeiro: Lúmen Juris, 2010. p. 135-146.

GIL, A. C. Métodos e técnicas de pesquisa social. 5. ed. São Paulo: Atlas, 1999. 
GRAMSCI, A. Maquiavel, a política e o Estado moderno. Rio de Janeiro: Civilização Brasileira, 1980.

IAMAMOTO, M. V. O Serviço Social na contemporaneidade: trabalho e formação profissional. 20. ed. São Paulo: Cortez, 2011.

INOJOSA, R. M. Sinergia em políticas e serviços públicos: desenvolvimento social com intersetorialidade. Cadernos Fundap, v. 22, p. 102-110, 2001. Disponível em:

$<$ http://www.pucsp.br/prosaude/downloads/bibliografia/sinergia_politicas_servicos_pub licos.pdf>. Acesso em: 22 jul. 2016.

IBGE. Sinopse do Senso Demográfico de 2010. Rio de Janeiro, 2011. Disponível em: <http://www.ibge.gov.br/home/estatistica/populacao/censo2010/default_sinopse.shtm>. Acesso em: 22 jul. 2016.

MINAYO, M. C. S. (Org.). Pesquisa social: teoria, método e criatividade. 5. ed. Rio de Janeiro: Vozes, 1996.

MINAYO, M. C. S. O desafio do conhecimento: pesquisa qualitativa em saúde. 12. ed. São Paulo: Hucitec, 2010.

MIOTO, R. C. Família; trabalho com família e Serviço Social. Serviço Social em Revista, Londrina, v. 12, n. 2, p. 163-176, jan./jun. 2010. Disponível em:

<http://www.uel.br/revistas/uel/index.php/ssrevista/article/view/7584/6835>. Acesso em: 22 jul. 2016.

PEREIRA-PEREIRA, P. A. Mudanças estruturais, política social e papel da família: crítica ao pluralismo de bem-estar. In: SALES, M. A.; MATOS, M. C. de; LEAL, M.C. (Org.). Política social, família e juventude: uma questão de direitos. 2. ed. São Paulo: Cortez, 2006. p. 2542.

POLLO, S. H. L.; ASSIS, M. Instituições de longa permanência para idosos - ILPIS: desafios e alternativas no município do Rio de Janeiro. In: Revista Brasileira de Geriatria e Gerontologia, Rio de Janeiro, v. 11, n. 1, p.1-18, 2008.

PONTES, R. N. Mediação e serviço social: um estudo preliminar sobre a categoria teórica e sua apropriação pelo serviço social. São Paulo: Cortez, 2007.

VIEIRA, E. B. Instituições geriátricas: avanço ou retrocesso? Rio de Janeiro: Revinter. 2003. 